\title{
Right Lower Forearm
}

National Cancer Institute

\section{Source}

National Cancer Institute. Right Lower Forearm. NCI Thesaurus. Code C105643.

The distal half of the right upper limb between the elbow and the wrist. 